\title{
Óleo e torta de dendê em rações para juvenis de tilápia-do-nilo
}

\author{
Rafael Vieira de Azevedo(1), William Cristiane Teles Tonini(2) e Luís Gustavo Tavares Braga( ${ }^{(3)}$
}

\begin{abstract}
(1)Universidade Estadual do Norte Fluminense, Avenida Alberto Lamego, № 2.000, Horto, CEP 28015-620 Campos dos Goytacazes, RJ. E-mail: azevedorv84@gmail.com (2)Universidade do Estado da Bahia, Rua João Guimarães, s/non, Bairro São Francisco, CEP 47400-000 Xique-Xique, BA. E-mail: willcttonini@gmail.com ${ }^{(3)}$ Universidade Estadual de Santa Cruz, Rodovia Jorge Amado, Km 16, Salobrinho, CEP 45662-900 Ilhéus, BA. E-mail: Igtbraga@gmail.com
\end{abstract}

Resumo - O objetivo deste trabalho foi avaliar a inclusão da torta e do óleo de dendê em rações para tilápia-do-nilo. Foram utilizados 312 peixes, distribuídos em 24 tanques $(150 \mathrm{~L})$, em delineamento inteiramente casualizado, em arranjo fatorial $2 \times 3$ - duas fontes de óleo (soja ou dendê) e três níveis de torta de dendê $(0,15$ e $30 \%)$. A fonte de óleo não influenciou o desempenho zootécnico. A inclusão da torta de dendê não alterou a conversão alimentar aparente e a taxa de sobrevivência dos peixes; porém, promoveu aumento nos valores de consumo diário de ração, ganho de peso diário, taxa de crescimento específico e fator de condição. A fonte de óleo e a inclusão da torta não influenciaram o teor de gordura e o rendimento de carcaça, o índice hepatossomático, o valor produtivo da energia e o colesterol plasmático. $\mathrm{O}$ óleo de dendê pode substituir o óleo de soja, e a inclusão da torta de dendê melhora o desempenho zootécnico de tilápias-do-nilo, sem alterar características corporais e sanguíneas.

Termos para indexação: Elaeis guineenses, Oreochromis niloticus, alimentos alternativos, desempenho, piscicultura intensiva.

\section{Palm oil and palm kernel cake in diets for juvenile Nile tilapia}

\begin{abstract}
The objective of this work was to evaluate the inclusion of palm kernel cake and palm oil in diets for Nile tilapia. Three hundred and twelve fish were distributed in 24 tanks $(150 \mathrm{~L})$ in a completely randomized design, in a $2 \times 3$ factorial arrangement - two oil sources (soybean or palm oil) and three levels of palm kernel cake $(0,15$, and $30 \%)$. The oil source did not influence animal performance. The inclusion of palm kernel cake did not affect apparent feed conversion and survival rate of fish; however, it increased values of daily feed intake, daily weight gain, specific growth rate, and condition factor. The oil source and the inclusion of the palm kernel cake did not influence the fat content and carcass yield, the hepatosomatic index, the value of productive energy, and plasma cholesterol. Palm oil can replace soybean oil, and the inclusion of palm kernel cake improves the growth performance of Nile tilapia, without altering body and blood characteristics.
\end{abstract}

Index terms: Elaeis guineenses, Oreochromis niloticus, alternative feed, performance, intensive fish production.

\section{Introdução}

A tilápia-do-nilo (Oreochromis niloticus) vem ocupando lugar de destaque na piscicultura brasileira e representou cerca de $70 \%$ da produção em 2010 (Ministério da Pesca e Aquicultura, 2012). Essa espécie apresenta características desejáveis para a piscicultura, como rápido crescimento, excelente desempenho em sistemas intensivos de produção, hábito alimentar onívoro e facilidade em aceitar rações, desde o período de pós-larva até a fase de terminação (Furuya et al., 2008).

Ocultivo intensivo de peixes requer a utilização de uma alimentação balanceada, à base de rações formuladas com os mais diversos ingredientes e processos de elaboração, para um melhor aproveitamento pelos peixes e uma maior produtividade (Silva et al., 2003). Dessa forma, o custo com a alimentação pode representar até $70 \%$ dos custos de produção da piscicultura intensiva (Guimarães et al., 2008). Uma das alternativas para baratear esses custos é o uso de ingredientes alternativos introduzidos nas formulações das rações (Carvalho et al., 2012).

A farinha e o óleo de peixe, fontes tradicionalmente utilizadas na formulação de rações para organismos aquáticos, tendem a elevar os custos de produção. Assim, são necessários estudos de fontes alternativas para esses ingredientes, sem, no entanto, comprometer a qualidade da água e o desempenho dos peixes (Mourente et al., 2005; Lopes et al., 2010).

O dendezeiro (Elaeis guineenses) é uma palmeira originária da costa ocidental da África, que foi introduzida no continente americano a partir do século 15. Essa palmeira é a oleaginosa de maior produtividade 
conhecida no mundo, e seus subprodutos têm razoável disponibilidade no mercado, com baixo custo na Região Nordeste do Brasil (Rodrigues Filho et al., 2001). Por meio da prensagem das amêndoas, o óleo é extraído, e o produto resultante da polpa seca do dendê (torta) pode ser utilizado como componente de ração para animais (Rodrigues Filho et al., 2001; Oliveira et al., 2011; Ribeiro et al., 2011).

A torta de dendê apresenta excelente perfil aminoacídico e é indicada para compor rações para animais (Omoregie, 2001), e o óleo de dendê é considerado um potencial substituto ao óleo de peixe ( $\mathrm{Ng}$ et al., 2006). Óleos de origem vegetal são boas fontes de energia para peixes de clima tropical, facilmente encontrados no mercado, que podem ser utilizados dependendo do custo e da disponibilidade da matéria-prima em cada região (Vargas et al., 2007).

O objetivo deste trabalho foi avaliar a inclusão da torta e do óleo de dendê em rações para tilápia-do-nilo.

\section{Material e Métodos}

O experimento foi realizado no Laboratório de Nutrição e Alimentação de Peixes da Universidade Estadual de Santa Cruz, Ilhéus, BA, durante 55 dias, entre janeiro e março de 2011.

Foram utilizados 312 juvenis de tilápia-do-nilo, machos, revertidos sexualmente, com peso inicial de $51,97 \pm 3,10 \mathrm{~g}$, distribuídos em 24 tanques cilíndricos de fibra de vidro, com capacidade de $150 \mathrm{~L}$ de volume útil. Utilizou-se o delineamento inteiramente casualizado, em arranjo fatorial $2 \times 3$ (fonte de óleo $\mathrm{x}$ níveis de inclusão da torta de dendê), com quatro repetições, tendo-se considerado, como unidade experimental, um tanque com 13 peixes.

Os tanques foram mantidos em sistema de recirculação contínua de água, tendo-se utilizado filtro biológico, com vazão de 1,4 $\mathrm{L} \mathrm{min}^{-1}$ em cada tanque, com uso de bomba d'água. Cada tanque continha aeração individual feita por meio de pedra porosa alimentada por soprador de $1 \mathrm{cv}$. Ao longo de todo o experimento, foram mensurados parâmetros de temperatura, $\mathrm{pH}$ e oxigênio dissolvido, com uso de analisador multiparâmetro digital YSI 55-12, (YSI Incorporated, Yellow Springs, OH, EUA), diariamente, pela manhã e pela tarde. Semanalmente, foi verificado o teor de amônia na água por meio de fotocolorímetro Hanna HI83203, (Hanna Instruments Inc., Woonsocket, RI, EUA).
Foram elaboradas seis rações isocalóricas e isoproteicas, com 0,15 e $30 \%$ de inclusão da torta de dendê, tendo-se alternado a fonte de óleo (soja ou dendê) para cada nível de inclusão (Tabela 1). A formulação foi feita de acordo com as exigências para a espécie, segundo Furuya (2010), e com os coeficientes de digestibilidade aparente obtidos por Braga et al. (2010).

Para a elaboração das rações, os alimentos foram processados individualmente em um moinho tipo faca, com peneira de $0,5 \mathrm{~mm}$. Posteriormente, os alimentos foram misturados de acordo com a formulação de cada ração e umedecidos com água para serem peletizados e secos em estufa, a $55^{\circ} \mathrm{C}$, por 48 horas. Para o fornecimento às tilápias, as rações foram desintegradas de modo a apresentarem granulometrias ajustadas ao tamanho da boca dos peixes e fornecidas à vontade até a saciedade aparente, duas vezes ao dia.

Ao início do experimento, foram realizadas, individualmente, as medidas individuais de peso $(0,01 \mathrm{~g})$ e comprimento total $(0,01 \mathrm{~cm})$ de todos os peixes das unidades experimentais. O mesmo procedimento, com todos os peixes sobreviventes, foi realizado aos 55 dias de experimento. A mortalidade foi registrada diariamente. A partir dos dados obtidos por meio das biometrias, foram determinados: consumo diário de ração [(consumo total/período experimental) x 100], ganho de peso diário [(peso final - peso inicial)/período experimental], conversão alimentar aparente (consumo de ração/ganho de peso), taxa de crescimento específico [ $\operatorname{Ln}$ (peso final) $\mathrm{Ln}$ (peso inicial)/período experimental x 100], fator de condição [(peso corporal/comprimento padrão) ${ }^{3} \times 100$ ] e taxa de sobrevivência [(indivíduos mortos/indivíduos vivos) $\mathrm{x}$ 100], como avaliação do desempenho zootécnico.

No início do experimento, antes da aplicação dos tratamentos, dez peixes foram abatidos, eviscerados e congelados para posteriores análises dos teores de gordura e energia bruta na carcaça. Ao final do período experimental, o mesmo procedimento foi adotado com quatro peixes de cada repetição, tendo-se realizado a pesagem dos fígados.

Para a análise de gordura da carcaça, as tilápias foram secas em estufa de ventilação forçada $\left(65^{\circ} \mathrm{C}\right)$ por 72 horas e trituradas para posterior análise, segundo Silva \& Queiroz (2006). Foram determinados: rendimento de carcaça [(peso do peixe eviscerado/peso final) x 100], índice hepatossomático [(peso do fígado/

Pesq. agropec. bras., Brasília, v.48, n.8, p.1028-1034, ago. 2013 DOI: 10.1590/S0100-204X2013000800031 
peso corporal) $\mathrm{x}$ 100] e valor produtivo da energia $\{[($ peso final $\mathrm{x}$ energia bruta corporal final) - (peso inicial $\mathrm{x}$ energia bruta corporal inicial)/energia bruta consumida] x 100$\}$.

Para a análise dos níveis de colesterol total plasmático, após a última biometria dos peixes, foram retirados, aleatoriamente, dois peixes de cada repetição para coleta de sangue por punção cardíaca, tendo-se utilizado seringa previamente heparinizada. O colesterol foi quantificado pelo método proposto por Alain et al. (1974), com uso de kit comercial Labtest Diagnóstica, conforme recomendação do fabricante, em analisador bioquímico automático Labmax Plenno (Labtest Diagnóstica S.A., Belo Horizonte, MG).

Os dados obtidos foram submetidos à análise de variância bifatorial, a 5\% de probabilidade, e, quando observadas diferenças significativas, aplicou-se o teste de Tukey, com uso do programa estatístico SAS.

\section{Resultados e Discussão}

Os valores dos parâmetros físicos e químicos da água foram, em média, $28,2 \pm 1,1^{\circ} \mathrm{C}, 6,8 \pm 0,1$ e
$4,8 \pm 0,8 \mathrm{mg} \mathrm{L}^{-1}$, respectivamente, para temperatura, $\mathrm{pH}$ e oxigênio dissolvido, tendo permanecido dentro da faixa adequada para a criação de peixes (Moreira et al., 2001). Os valores de amônia foram, em média, $0,09 \pm 0,01 \mathrm{mg} \mathrm{L}^{-1}$ durante o período experimental.

Não foi observado efeito da interação entre fonte de óleo utilizada e nível de inclusão da torta de dendê na ração sobre desempenho zootécnico, gordura e rendimento de carcaça, índice hepatossomático, valor produtivo da energia e colesterol plasmático (Tabelas 2 e 3).

Também não foi observada influência da fonte de óleo utilizada sobre os parâmetros de desempenho zootécnico avaliados (Tabela 2).

Vargas et al. (2007) não constataram influência da fonte de diferentes tipos de óleo (milho e linhaça) sobre as variáveis ganho de peso, consumo de ração diário, taxa de crescimento específico, conversão alimentar aparente, taxa de eficiência proteica e sobrevivência de tilápias com peso médio inicial de $8,3 \pm 1,5 \mathrm{~g}$. Para a mesma espécie (peso médio inicial de 0,26 $\pm 0,01 \mathrm{~g}$ ), Matsushita et al. (2006) não relataram diferenças significativas sobre as variáveis ganho de peso e

Tabela 1. Composição percentual da ração com $0 \%$ de torta de dendê, com óleo de soja (0S) e com óleo de dendê (0D); da ração com $15 \%$ de torta de dendê, com óleo de soja (15S) e com óleo de dendê (15D); e da ração com $30 \%$ de torta de dendê, com óleo de soja (30S) e com óleo de dendê (30D).

\begin{tabular}{|c|c|c|c|c|c|c|}
\hline Ingrediente (\%) & $0 \mathrm{~S}$ & $0 \mathrm{D}$ & $15 \mathrm{~S}$ & $15 \mathrm{D}$ & $30 \mathrm{~S}$ & $30 \mathrm{D}$ \\
\hline Farelo de soja & 41,00 & 41,00 & 35,46 & 37,42 & 32,78 & 35,00 \\
\hline Farelo de trigo & 25,00 & 25,00 & 12,50 & 12,50 & 4,50 & 4,50 \\
\hline Fubá de milho & 20,00 & 20,00 & 8,06 & 10,02 & 6,00 & 6,00 \\
\hline Farinha de peixe & 7,97 & 7,97 & 12,83 & 12,00 & 15,00 & 15,00 \\
\hline Amido & 3,40 & 3,41 & 12,00 & 9,93 & 8,03 & 5,93 \\
\hline Torta de dendê & - & - & 15,00 & 15,00 & 30,00 & 30,00 \\
\hline Óleo de soja & 1,61 & - & 2,13 & - & 2,57 & - \\
\hline Óleo de dendê & - & 1,60 & - & 2,11 & - & 2,53 \\
\hline Suplemento (mineral e vitamínico) ${ }^{(1)}$ & 1,00 & 1,00 & 1,00 & 1,00 & 1,00 & 1,00 \\
\hline Antioxidante BHT & 0,02 & 0,02 & 0,02 & 0,02 & 0,02 & 0,02 \\
\hline $\mathrm{L}$ lisina $\mathrm{HCl}$ & - & - & - & - & 0,10 & 0,02 \\
\hline \multirow[t]{2}{*}{ Total } & 100,00 & 100,00 & 100,00 & 100,00 & 100,00 & 100,00 \\
\hline & \multicolumn{6}{|c|}{ Valores calculados } \\
\hline Proteína digestível (\%) & 25,48 & 25,48 & 25,00 & 25,19 & 25,00 & 25,93 \\
\hline Energia bruta $\left(\mathrm{kcal} \mathrm{kg}^{-1}\right)^{(2)}$ & 4.125 & 4.292 & 4.314 & 4.229 & 4.240 & 4.423 \\
\hline Energia digestível $\left(\mathrm{kcal} \mathrm{kg}^{-1}\right)$ & 3.078 & 3.070 & 3.010 & 3.010 & 3.000 & 3.000 \\
\hline Fibra bruta $(\%)$ & 5,12 & 5,12 & 6,53 & 6,62 & 8,57 & 8,70 \\
\hline Gordura (\%) & 4,30 & 4,30 & 4,30 & 4,30 & 4,50 & 4,50 \\
\hline Lisina total & 1,65 & 1,65 & 1,60 & 1,60 & 1,60 & 1,60 \\
\hline
\end{tabular}

(1)Composição por quilograma: Mg, 2.600 mg; Zn, 14.000 mg; Fe, 10.000 mg; Cu, 1.400 mg; Co, 20 mg; I, 60 mg; Se, 60 mg; vitamina A, 1.000 .000 UI; vitamina D3, $400.000 \mathrm{UI}$; vitamina E, $10.000 \mathrm{mg}$; vitamina K3, $500 \mathrm{mg}$; vitamina B1, 2,500 mg; vitamina B2, $2.500 \mathrm{mg}$; vitamina B6, 2.500 mg; vitamina B12, $3.000 \mathrm{mcg}$; vitamina C, $35.000 \mathrm{mg}$; ácido fólico, $500 \mathrm{mg}$; ácido pantotênico, $5.000 \mathrm{mg}$; niacina, $10.000 \mathrm{mg}$; biotina, $80.000 \mathrm{mcg}$; colina, 200.000 mg; metionina, $130 \mathrm{~g}$; inositol, $5.000 \mathrm{mg}$; etoxiquin, $15.000 \mathrm{mg} .{ }^{(2)}$ Valor analisado por meio de bomba calorimétrica IKA C-200 (IKA-Werke Gmbh \& Co, Staufen, Alemanha). 
conversão alimentar aparente, ao testar diferentes fontes lipídicas (óleos de soja, canola, girassol, linhaça, arroz e milho).

Valores superiores para taxa de crescimento especifico $(1,88 \%$ por dia) e conversão alimentar aparente $(1,45: 1)$, e inferiores para sobrevivência $(85,6 \%)$ foram obtidos por Bahurmiz \& $\mathrm{Ng}$ (2007), ao avaliar o uso do óleo de dendê $(8 \%)$ em rações para tilápia vermelha híbrida $(31,3 \pm 0,1 \mathrm{~g})$.

O óleo de soja e o óleo de dendê são fontes de ácidos graxos essenciais, como o linoleico (Bahurmiz \& Ng, 2007; Ribeiro et al., 2008), e o requerimento deste pela tilápia-do-nilo é de $0,5 \%$ (National Research Council, 1993). Possivelmente, a exigência nesse ácido graxo tenha sido atendida em todas as rações experimentais, as quais foram nutricionalmente semelhantes, tendo fornecido energia e ácidos graxos essenciais na mesma proporção, sem influenciar o desempenho zootécnico dos peixes.
A inclusão da torta de dendê não alterou a conversão alimentar aparente e a taxa de sobrevivência, para as quais se obteve média de 1,27:1 e 92,3\%, respectivamente (Tabela 2 ).

A inclusão da torta de dendê na ração elevou os valores de consumo diário de ração, ganho de peso diário, taxa de crescimento específico e fator de condição dos indivíduos avaliados. Não foi observada diferença significativa entre os níveis de inclusão de 15 e $30 \%$.

Oliveira et al. (1997), ao avaliar a torta de dendê em rações para tilápia-do-nilo $(1,52 \pm 0,04 \mathrm{~g})$, não observaram efeito da inclusão de até $35 \%$ na ração sobre ganho de peso, conversão alimentar e taxa de crescimento especifico. Ao analisar diferentes níveis de inclusão da torta de dendê $(0,10,20$ e $30 \%)$, para Labeo senegalensis $(3,53 \pm 0,02 \mathrm{~g})$, Omoregie (2001) obteve piores resultados para ganho de peso, taxa de

Tabela 2. Desempenho zootécnico de tilápias do nilo (Oreochromis niloticus) de acordo com a fonte de óleo e o nível de inclusão da torta de dendê na ração ${ }^{(1)}$.

\begin{tabular}{|c|c|c|c|c|c|c|}
\hline \multirow[t]{2}{*}{ Tratamento } & \multicolumn{6}{|c|}{ Variável $^{(2)}$} \\
\hline & CDR (g por dia) & GPD (g por dia) & $\mathrm{CAA}\left(\mathrm{g} \mathrm{g}^{-1}\right)$ & TCE $(\%$ por dia $)$ & $\mathrm{FC}(\%)$ & SOB $(\%)$ \\
\hline Óleo de soja & 1,37 & 1,08 & 1,28 & 1,39 & 1,72 & 94,69 \\
\hline Óleo de dendê & 1,38 & 1,09 & 1,26 & 1,37 & 1,73 & 89,90 \\
\hline Torta de dendê $0 \%$ & $1,13 \mathrm{~b}$ & $0,91 b$ & 1,25 & $1,20 \mathrm{~b}$ & $1,66 \mathrm{~b}$ & 89,77 \\
\hline Torta de dendê $15 \%$ & $1,44 \mathrm{a}$ & $1,14 \mathrm{a}$ & 1,27 & $1,43 \mathrm{a}$ & $1,73 \mathrm{a}$ & 96,21 \\
\hline Torta de dendê $30 \%$ & $1,55 \mathrm{a}$ & $1,22 \mathrm{a}$ & 1,29 & $1,52 \mathrm{a}$ & $1,78 \mathrm{a}$ & 90,90 \\
\hline $\mathrm{CV}(\%)$ & 10,56 & 10,80 & 13,04 & 7,19 & 4,21 & 9,41 \\
\hline Fonte & 0,8245 & 0,7580 & 0,8060 & 0,6564 & 0,8676 & 0,1927 \\
\hline Nível & 0,0001 & 0,0001 & 0,8955 & 0,0001 & 0,0128 & 0,3092 \\
\hline Fonte x Nível & 0,9758 & 0,9196 & 0,8940 & 0,4704 & 0,9696 & 0,1126 \\
\hline
\end{tabular}

${ }^{(1)}$ Médias seguidas de letras diferentes, nas linhas, diferem pelo teste de Tukey, a $\%$ de probabilidade. ${ }^{(2)} \mathrm{CDR}$, consumo diário de ração; GPD, ganho de peso diário; CAA, conversão alimentar aparente; TCE, taxa de crescimento específico; FC, fator de condição; SOB, taxa de sobrevivência.

Tabela 3. Índices de carcaça, valor produtivo da energia (VPE) e colesterol plasmático (CP) de tilápias-do-nilo (Oreochromis niloticus) de acordo com a fonte de óleo e o nível de inclusão da torta de dendê na ração ${ }^{(1)}$.

\begin{tabular}{|c|c|c|c|c|c|}
\hline \multirow[t]{2}{*}{ Tratamento } & \multicolumn{5}{|c|}{ Variável $^{(2)}$} \\
\hline & $\mathrm{GC}(\%)$ & $\mathrm{RC}(\%)$ & IHS (\%) & VPE (\%) & $\mathrm{CP}\left(\mathrm{mg} \mathrm{dL}^{-1}\right)$ \\
\hline Óleo de soja & 21,12 & 88,51 & 2,75 & 72,25 & 119,19 \\
\hline Óleo de dendê & 20,35 & 87,86 & 2,89 & 72,71 & 120,58 \\
\hline Torta de dendê $0 \%$ & 20,91 & 87,71 & 2,61 & 76,56 & 119,67 \\
\hline Torta de dendê $15 \%$ & 20,74 & 88,18 & 2,93 & 71,34 & 120,37 \\
\hline Torta de dendê $30 \%$ & 20,56 & 88,65 & 2,93 & 69,54 & 119,63 \\
\hline $\mathrm{CV}(\%)$ & 8,12 & 2,36 & 17,53 & 15,53 & 11,83 \\
\hline Fonte de óleo & 0,2311 & 0,4532 & 0,4745 & 0,9221 & 0,8395 \\
\hline Nível de torta de dendê & 0,9030 & 0,6710 & 0,3681 & 0,4488 & 0,9948 \\
\hline Fonte x Nível & 0,1337 & 0,4998 & 0,8090 & 0,8908 & 0,9765 \\
\hline
\end{tabular}

${ }^{(1)}$ Médias seguidas de letras diferentes, nas linhas, diferem pelo teste de Tukey, a $5 \%$ de probabilidade. ${ }^{(2)} \mathrm{GC}$, gordura na carcaça; $\mathrm{RC}$, rendimento de carcaça; IHS, índice hepatossomático. 
crescimento específico e conversão alimentar aparente, nos níveis de 20 e $30 \%$ de inclusão da torta de dendê.

Uma dificuldade comum observada quando fontes alternativas de alimentos são utilizadas em rações para peixes é a aceitabilidade, a qual é relacionada à palatabilidade (Rodríguez-Serna, 1996). No presente trabalho, o aumento nos valores de consumo diário de ração sugere que a inclusão da torta de dendê tenha melhorado a palatabilidade da ração.

A fonte de óleo utilizada (soja ou dendê) não influenciou o rendimento e a gordura da carcaça, o índice hepatossomático, o valor produtivo da energia e o colesterol plasmático. De modo semelhante, não foi observada influência da inclusão da torta de dendê nas rações experimentais sobre as mesmas variáveis dos peixes (Tabela 3 ).

Valores superiores para rendimento de carcaça $(95,10 \%)$ e inferiores para índice hepatossomático $(1,80 \%)$ foram encontrados por Bahurmiz \& $\mathrm{Ng}$ (2007), ao avaliar a inclusão do óleo de dendê em rações para tilápia vermelha híbrida. Omoregie (2001) também não observou efeito dos níveis de inclusão de torta de dendê sobre a gordura na carcaça e o índice hepatossomático de L. senegalensis. No entanto, Oliveira et al. (1997) relataram redução nos valores da gordura corporal à medida que se aumentou o nível de torta de dendê na ração (de $0 \%$ para $35 \%$ ) e se reduziu os níveis de óleo de soja (de $8 \%$ para $1 \%$ ), o que não foi verificado no presente trabalho.

Diferentemente dos resultados obtidos no presente trabalho, Losekann et al. (2008) observaram efeito da fonte de lipídio utilizada sobre a composição de gordura na carcaça. Esses autores sugeriram que a melhor relação entre ácidos graxos ômega 3 e ômega 6 presentes em cada fonte de óleo pode ser responsável pela menor percentagem de gordura na carcaça.

Não houve efeito das rações sobre o índice hepatossomático (Tabela 3). Segundo Santos et al. (2009) e Lopes et al. (2010), a possível presença de fatores antinutricionais nos alimentos alternativos de origem vegetal pode comprometer o funcionamento normal do organismo dos peixes, o que causa problemas no seu metabolismo, com consequente diminuição do índice hepatossomático. De acordo com Oliveira et al. (1998), a inclusão da torta de dendê em rações para tilápia-do-nilo não afeta o padrão de normalidade do aparelho digestivo, o que indica o potencial desse ingrediente, de baixo custo, como componente de rações para essa espécie de peixe.

Não houve efeito dos tratamentos sobre o colesterol plasmático. Os valores obtidos (média de $120 \mathrm{mg} \mathrm{dL}^{-1}$ ) são compatíveis com os encontrados em trabalhos já realizados com a espécie. Cabe ressaltar que o teor de colesterol plasmático pode ser utilizado como indicativo da saúde dos peixes, que, ao serem mantidos em ambiente insalubre, apresentam redução nos valores deste parâmetro (Yoneyama et al., 2009).

Yoneyama et al. (2009) monitoraram os teores de colesterol plasmático, durante 30 dias, em tilápias (100$300 \mathrm{~g}$ ) e observaram variações de 74 a $480 \mathrm{mg} \mathrm{dL}^{-1}$. Já Francis et al. (2002), encontraram valores de $200 \mathrm{mg} \mathrm{dL}^{-1}$, em tilápias de $60 \mathrm{~g}$, e Metwally (2009) de 75 a $149 \mathrm{mg} \mathrm{dL}^{-1}$, em tilápias de $25 \mathrm{~g}$. Araújo et al. (2011), ao analisar o uso de óleos de linhaça e girassol para tilápia $(125 \mathrm{~g})$, relataram valores similares aos obtidos no presente trabalho $\left(134,5 \mathrm{mg} \mathrm{dL}^{-1}\right)$.

A quantidade de fibra nas rações pode influenciar o colesterol plasmático, pois reduz a capacidade de formação de micelas no intestino. Os polissacarídeos não amiláceos, por se ligarem aos sais biliares, impedem a absorção das gorduras, o que aumenta a excreção de colesterol nas fezes e reduz o colesterol circulante (Krögdahl et al., 2005). Entretanto, a variação do teor de fibra (5,1 a 8,7\%) nas rações não foi suficiente para alterar o valor do colesterol plasmático (Tabela 1).

\section{Conclusões}

1. O óleo de dendê pode substituir o óleo de soja em rações para tilápia-do-nilo, sem alterar o desempenho zootécnico e as características corporais.

2. A inclusão da torta de dendê melhora o desempenho zootécnico de tilápia-do-nilo, sem alterar características corporais, retenção de energia e nível de colesterol plasmático.

\section{Agradecimentos}

Ao Conselho Nacional de Desenvolvimento Científico e Tecnológico (CNPq) e à Coordenação de Aperfeiçoamento de Pessoal de Nível Superior (Capes), pelo apoio financeiro; à Fazenda Aguavale Piscicultura e Óleos de Palma S/A, pelo fornecimento dos insumos; e ao biomédico Vivaldo Mendonça Neto, pelo apoio na realização das análises de colesterol plasmático. 


\section{Referências}

ALAIN, C.A.; POON, L.S.; CAHN, C.S.G.; RICHMOND, W.; FU, P.C. Enzymatic determination of total serum cholesterol. Clinical Chemistry, v.20, p.470-475, 1974.

ARAÚJO, D. de M.; PEZZATO, A.C.; BARROS, M.M.; PEZZATO, L.E.; NAKAGOME, F.K. Hematologia de tilápias-do-nilo alimentadas com dietas com óleos vegetais e estimuladas pelo frio. Pesquisa Agropecuária Brasileira, v.46, p.294-302, 2011. DOI: 10.1590/S0100-204X2011000300010.

BAHURMIZ, O.M.; NG, W.K. Effects of dietary palm oil source on growth, tissue fatty acid composition and nutrient digestibility of red hybrid tilapia, Oreochromis sp., raised from stocking to marketable size. Aquaculture, v.262, p.382-392, 2007. DOI: 10.1016/j.aquaculture.2006.11.023.

BRAGA, L.G.T; RODRIGUES, F.L.; AZEVEDO, R.V. de; CARVALHO, J.S.O; RAMOS, A.P.S. Digestibilidade aparente da energia e nutrientes de coprodutos agroindustriais para tilápia do Nilo. Revista Brasileira de Saúde e Produção Animal, v.11, p.1127-1136, 2010.

CARVALHO, J.S.O.; AZEVEDO, R.V. de; RAMOS, A.P.S.; BRAGA, L.G.T. Agroindustrial byproducts in diets for Nile tilapia juveniles. Revista Brasileira de Zootecnia, v.41, p.479-484, 2012. DOI: 10.1590/S1516-35982012000300002.

FRANCIS, G.; LEVAVI-SIVAN, B.; AVITAN, A.; BECKER, K. Effects of long term feeding of Quillaja saponins on sex ratio, muscle and serum cholesterol and LH levels in Nile tilapia (Oreochromis niloticus (L.). Comparative Biochemistry and Physiology Part C, v.133, p.593-603, 2002. DOI: 10.1016/ S1532-0456(02)00167-9.

FURUYA, W.M. Tabelas Brasileiras para nutrição de tilápias. Toledo: GFM, 2010. 100p.

FURUYA, W.M.; FUJII, K.M.; SANTOS, L.D. dos; SILVA, T.S. de C.; SILVA, L.C.R. da; SALES, P.J.P. Exigência de fósforo disponível para juvenis de tilápia-do-nilo. Revista Brasileira de Zootecnia, v.37, p.1517-1522, 2008. DOI: 10.1590/ S1516-35982008000900001.

GUIMARÃES, I.G.; MIRANDA, E.C. de; RIBEIRO, V.L.; MARTINS, G.P.; MIRANDA, C.C. de. Farinha de camarão em dietas para tilápia do Nilo ("Oreochromis niloticus"). Revista Brasileira de Saúde e Produção Animal, v.9, p.140-149, 2008.

KRÖGDAHL, A.; HEMRE, G.I.; MOMMSEN, T.P. Carbohydrates in fish nutrition: digestion and absorption in post larval stages. Aquaculture Nutrition, v.11, p.103-122, 2005. DOI: 10.1111/j.1 365-2095.2004.00327.x

LOPES, J.M.; PASCOAL, L.A.F.; SILVA FILHO, F.P. da; SANTOS, I.B.; WATANABE, P.H.; ARAÚJO, D. de M.; PINTO, D.C.; OLIVEIRA, P.S. dos. Farelo de babaçu em dietas para tambaqui. Revista Brasileira de Saúde e Produção Animal, v.11, p.519-526, 2010.

LOSEKANN, M.E.; RADÜNZ NETO, J.R.; EMANUELLI, T.; PEDRON, F. de A.; LAZZARI, R.; BERGAMIN, G.T.; CORRÊIA, V.; SIMÕES, R.S. Alimentação do jundiá com dietas contendo óleos de arroz, canola ou soja. Ciência Rural, v.38, p.225-230, 2008. DOI: $10.1590 / \mathrm{S} 0103-84782008000100036$.

MATSUSHITA, M.; JUSTI, K.C.; PADRE, R. das G.; MILINSK, M.C.; HAYASHI, C.; GOMES, S.T.M.; VISENTAINER, J.V.; SOUZA, N.E. de. Influence of diets enriched with different vegetable oils on the performance and fatty acid profile of Nile tilapia (Oreochromis niloticus) fingerlings. Acta Scientiarum. Technology, v.28, p.125-131, 2006. DOI: 10.4025/actascitechnol. v28i2.1169.

METWALLY, M.A.A. Effect of garlic (Allium sativum) on some heavy metal (copper and zinc) induced alteration in serum lipid profile of Oreochromis niloticus. World Journal of Fish and Marine Sciences, v.1, p.1-6, 2009.

MINISTÉRIO DAPESCAEAQUICULTURA. Boletim estatístico da pesca e aquicultura 2010. Brasília: MPA, 2012. 129p.

MOREIRA, H.L.M.; VARGAS, L.; RIBEIRO, R.P.; ZIMERMANN, S. Fundamentos da moderna aqüicultura. Canoas: UFLA, 2001. 200p.

MOURENTE, G.; GOOD, J.E.; BELL, J.G. Partial substitution of fish oil with rapeseed, linseed and olive oils in diets for European sea bass (Dicentrarchus labrax L.): effects on flesh fatty acid composition, plasma prostaglandins E2 and F2a, immune function and effectiveness of a fish oil finishing diet. Aquaculture Nutrition, v.11, p.25-40, 2005. DOI: 10.1111/j.1365-2095.2004.0 0320.x.

NG, W.-K.; KOH, C.-B.; DIN, Z.-B. Palm oil-laden spent bleaching clay as a substitute for marine fish oil in the diets of Nile tilapia, Oreochromis niloticus. Aquaculture Nutrition, v.12, p.459-468, 2006. DOI: 10.1111/j.1365-2095.2006.00449.x.

NATIONAL RESEARCH COUNCIL. Nutrient requirements of warm water, fishes and shellfishes: nutrient requirements of domestic animals. Washington: National Academic Press, 1993. $114 \mathrm{p}$.

OLIVEIRA, A.C.B. de; PEZZATO, L.E.; BARROS, M.M.; PEZZATO, A.C.; SILVEIRA, A.C. Torta de dendê em dietas para a tilápia-do-Nilo: desempenho produtivo. Pesquisa Agropecuária Brasileira, v.32, p.443-449, 1997.

OLIVEIRA, A.C.B. de; PEZZATO, L.E.; BARROS, M.M.; GRANER, C.A.F. Digestibilidade aparente e efeito macro-microscópico em tilápia-do-nilo (Oreochromis niloticus) arraçoadas com torta de dendê. Revista Brasileira de Zootecnia, v.27, p.210-215, 1998 .

OLIVEIRA, R.L.; RIBEIRO, O.L.; BAGALDO, A.R.; LIMA, L. dos S.; BORJA, M.S.; CORREIA, B.R.; COSTA, J.B.; LEÃO, A.G. Torta de dendê oriunda da produção do biodiesel na ensilagem de capim-massai. Revista Brasileira de Saúde e Produção Animal, v.12, p.881-892, 2011.

OMOREGIE, E. Utilization and nutrient digestibility of mango seeds and palm kernel meal by juvenile Labeo senegalensis (Antheriniformes: Cyprinidae). Aquaculture Research, v.32, p.681-687, 2001. DOI: 10.1046/j.1365-2109.2001.00575.x.

RIBEIRO, P.A.P.; LOGATO, P.V.R.; PAULA, D.A. de J.; COSTA, A.C.; MURGAS, L.D.S.; FREITAS, R.T. de F. Efeito do uso de óleo na dieta sobre a lipogênese e o perfil lipídico de tilápias-do-nilo. 
Revista Brasileira de Zootecnia, v.37, p.1331-1337, 2008. DOI: 10.1590/S1516-35982008000800001.

RIBEIRO, R.D.X.; OLIVEIRA, R.L.; MACOME, F.M.; BAGALDO, A.R.; SILVA, M.C.A.; RIBEIRO, C.V.D.M.; CARVALHO, G.G.P.; LANNA, D.P.D. Meat quality of lambs fed on palm kernel meal, a by-product of biodiesel production. Asian Australasian Journal of Animal Sciences, v.24, p.1399-1406, 2011. DOI: 10.5713/ajas.2011.11110.

RODRIGUES FILHO, J.A.; CAMARÃO, A.P.; AZEVEDO, G.P.C. de. Utilização da torta de amêndoa de dendê na alimentação de ruminantes. Belém: Embrapa Amazônia Oriental, 2001. 24p. (Embrapa Amazônia Oriental. Documentos, 111).

RODRÍGUEZ-SERNA, M.; OLVERA-NOVOA, M.A.; CARMONA-OSALDE, C. Nutritional value of animal by-product meal in practical diets for Nile tilapia, Oreochromis niloticus (L.) fry. Aquaculture Research, v.27, p.67-73, 1996. DOI: 10.1111/ j.1365-2109.1996.tb00967.x.

SANTOS, E.L.; LUDKE, M. do C.M.M.; BARBOSA, J.M.; RABELLO, C.B.-V.; LUDKE, J.V.; WINTERLE, W. de M.C.; SILVA, E.G. da. Níveis de farelo de coco em rações para alevinos de tilápia do Nilo. Revista Brasileira de Saúde e Produção Animal, v.10, p.390-397, 2009.

SILVA, D.J.; QUEIROZ, A.C. Análise de alimentos: métodos químicos e biológicos. 3.ed. Viçosa: UFV, 2006. 235p.

SILVA, J.A.M. da; PEREIRA FILHO, M.; OLIVEIRA-PEREIRA, M.I. de. Frutos e sementes consumidos pelo tambaqui, Colossoma macropomum (Cuvier, 1818) incorporados em rações. Digestibilidade e velocidade de trânsito pelo trato gastrointestinal. Revista Brasileira de Zootecnia, v.32, p.1815-1824, 2003. DOI: 10.1590/S1516-35982003000800003.

VARGAS, R.J.; SOUZA, S.M.G. de; TOGNON, F.C.; GOMES, M.E.C.; KESSLER, A. de M. Desempenho de alevinos de tilápias do Nilo (Oreochromis niloticus), alimentados com dietas contendo diferentes fontes de lipídios. Revista Brasileira de Agrociência, v.13, p.377-381, 2007.

YONEYAMA, Y.; YONEMORI, Y.; MURATA, M.; OHNUKI, H.; HIBI, K.; HAYASHI, T.; REN, H.; ENDO, H. Wireless biosensor system for real-time cholesterol monitoring in fish "Nile tilapia". Talanta, v.80, p.909-915, 2009. DOI: 10.1016/j. talanta.2009.08.014.

Recebido em 27 de junho de 2011 e aprovado em 13 de novembro de 2012 